\title{
Ausgezeichnete Innovationen
}

Im Rahmen einer Gala in Berlin am 19. Oktober 2017 im Kongresszentrum Axica ist der von Springer Medizin gestiftete Galenus-von-Pergamon-Preis für pharmazeutische Innovationen verliehen worden. Darüber hinaus wurde mit dem CharityAward 2017 auch ehrenamtliches Engagement im Gesundheitswesen gewürdigt.

Mit dem alljährlichen Galenus-von-Pergamon-Preis zeichnet Springer Medizin herausragende Leistungen in der Pharmakologie aus. Schirmherrin hierfür ist die Bundesforschungsministerin Professor Johanna Wanka. Stellvertretend für die Ministerin überreichte der Parlamentarische Staatssekretär im Bundesministerium für Bildung und Forschung, Dr. Georg Schütte, in diesem Jahr am 19. Oktober die Preise auf einer Gala im Berliner Kongresszentrum Axica. Die Preisträger waren am Nachmittag zuvor in geheimer Abstimmung durch 14 Experten und unter dem Juryvorsitz von Professor Erland Erdmann ermittelt worden.

\section{Grundlagenforschung}

In der Kategorie „Pharmakologische Grundlagenforschung“ nahm die Forschergruppe um Professor Florian Bassermann von der Technischen Universität München die Auszeichnung entgegen. Die Wissenschaftler der Abteilung Hämatologische/ Internistische Onkologie der III. Medizinischen Klinik und Poliklinik beschrieben erstmals den molekularen Mechanismus, der für die Antitumorwirkung immunmodulierender Substanzen (IMiDs) verantwortlich ist.

Sie fanden heraus, dass diese Arzneimittel Krebszellen schädigen, indem sie einen Komplex der Zelleiweiße CD147 und MCT1 destabilisieren. Diese grundlegende Entdeckung kann in der Zukunft den Weg der Entwicklung neuer Medikamente zur Krebstherapie ebnen.

\section{Primary Care}

Den diesjährigen Galenus-Preis in der Kategorie „Primary Care“ bekam das Medikament Entresto ${ }^{\varpi}$ von Novartis. Die Fixkombination von Sacubitril und Valsartan ist der erste verfügbare Angiotensin-Rezeptor-Neprilysin-Inhibitor (ARNI). Er kann bei Patienten mit symptomatischer chronischer Herzinsuffizienz und reduzierter Ejektionsfraktion das Überleben verlängern.

\section{Specialist Care}

In der Kategorie „Specialist Care“ vergab die Jury den Preis an Cinqaero ${ }^{\star}$ Das Arzneimittel von Teva enthält Reslizumab, einen Antikörper gegen Interleukin-5 (IL-5). Er reduziert die Zahl eosinophiler Granulozyten und führt so bei Patienten mit schwerem eosinophilem Asthma bronchiale zur Verringerung der Exazerbationsfrequenz sowie zur Verbesserung von Lungenfunktion und Lebensqualität.

\section{Orphan Drugs}

Die Kategorie „Orphan Drugs“ wurde für Innovationen für Patienten mit einer seltenen Krankheit geschaffen. Gewinner in diesem Jahr ist Venclyxto ${ }^{\circledR}$. Das Präparat von AbbVie mit Venetoclax ist der erste orale Inhibitor des B-Zell-Lymphom-2-Proteins (BCL-2), der zur Behandlung von Hochrisikopatienten mit chronischer lymphatischer Leukämie zugelassen ist.

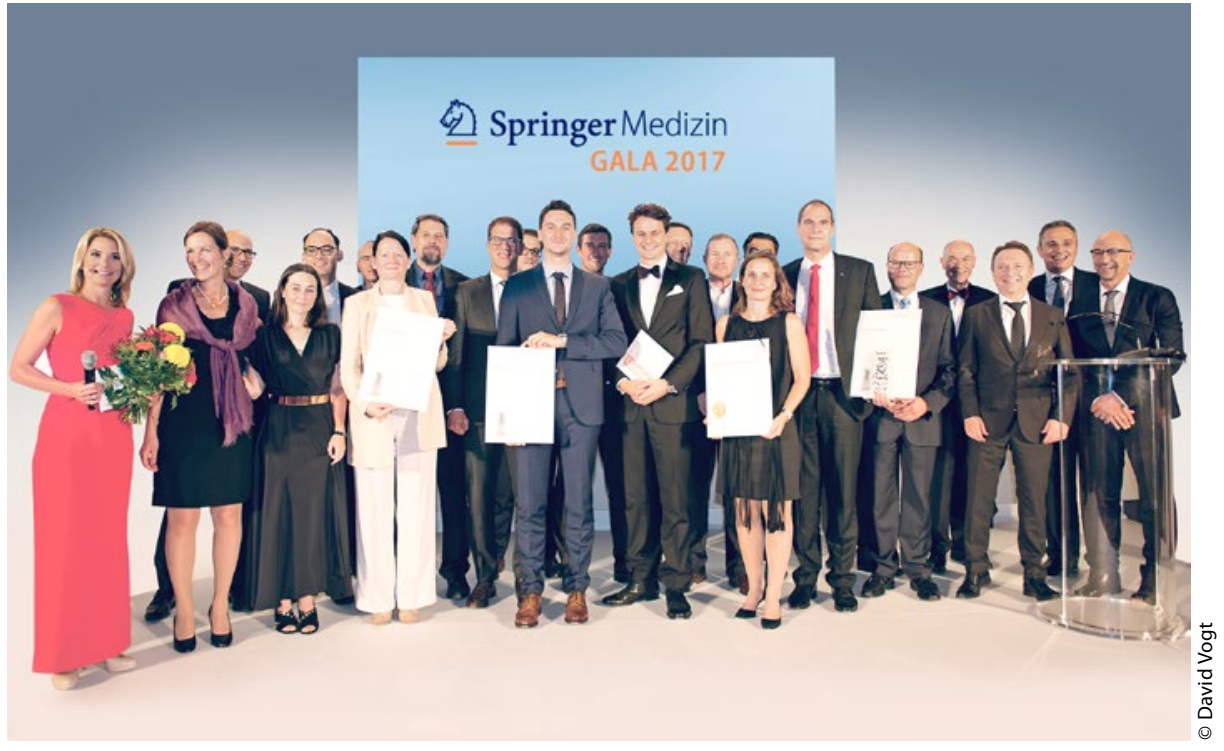

Alle diesjährigen Preisträger bei der großen Springer-Medizin-Gala am 19. Oktober.

\section{CharityAward 2017}

Mit dem CharityAward zeichnet Springer Medizin unter der Schirmherrschaft von Bundesgesundheitsminister Hermann Gröhe ehrenamtliches Engagement von Stiftungen, Organisationen und Institutionen im Gesundheitswesen aus.

Platz 1 belegte das Präventionsprojekt "Streetwork+" der Off Road Kids Stiftung und Bahn-BKK. Es klärt junge, auf der Straße lebende Menschen über Gesundheitsrisiken auf.

Platz 2 ging an die Münchner Studenteninitiative AIAS, die über Blutkrebs aufklärt und eine Registrierung zum Stammzellspender direkt am Campus ermöglicht.

Platz 3 machte die Deutsche Stiftung für junge Erwachsene mit Krebs. Ihr Projekt "Junges Krebsportal“ unterstützt 18- bis 39-jährige Patienten. 